\title{
Plasma MicroRNA-29c Levels Are Associated with Carotid Intima-Media Thickness and is a Potential Biomarker for the Early Detection of Atherosclerosis
}

\author{
Yu-Qing Huang Jie Li Cheng Huang Ying-Qing Feng \\ Department of Cardiology, Guangdong Cardiovascular Institute, Guangdong Provincial Key Laboratory \\ of Coronary Heart Disease Prevention, Hypertension Research Laboratory, Guangdong General \\ Hospital, Guangdong Academy of Medical Sciences, South China University of Technology School of \\ Medicine, Guangzhou, China
}

\section{Key Words}

Atherosclerosis • MicroRNAs $\cdot \operatorname{miR}-29 c \cdot C$-reactive protein $\cdot$ Subclinical atherosclerosis

\begin{abstract}
Background/Aims: Atherosclerosis is a serious disease that increases the risk of myocardial infarction and ischemic stroke. Previous studies have demonstrated that microRNA (miR)-29c could play significant roles in atherosclerosis via regulating inflammatory processes. However, the relationship between miR-29c and carotid intima-media thickness (CIMT) remains unknown. This study investigated associations between miR-29c and atherosclerosis and tested whether plasma miR-29c levels could be used to detect atherosclerosis. Methods: Plasma miR-29c levels were estimated by quantitative real-time PCR, and CIMT was measured by carotid ultrasound. Associations between miR-29c and CIMT were assessed by Spearman's correlation coefficient and multiple linear regression analyses. Results: In total, 170 participants were divided into the study (CIMT $\geqslant 0.9 \mathrm{~mm}$ ) and control (CIMT $<0.9 \mathrm{~mm}$ ) groups. The study group showed higher C-reactive protein (CRP) and miR-29c relative expression levels compared with the control group. CIMT was positively correlated with miR-29c $(r=0.659, p<0.001)$ and CRP $(r=0.447$, $p<0.001)$, and miR-29c levels were also correlated with CRP $(r=0.512, p<0.001)$. Furthermore, multiple linear regression analysis showed that CIMT was significantly correlated with miR$29 \mathrm{c}(\beta=0.573,95 \%$ confidence interval $[C I]$ : 0.315-0.839; $p<0.001)$ and CRP $(\beta=0.439,95 \% \mathrm{CI}$ : $0.186-0.825 ; p<0.001)$. After age, body mass index, systolic blood pressure, total cholesterol and fasting blood-glucose were adjusted for, CIMT was still closely associated with miR-29c $(\beta=0.529,95 \% C I: 0.354-0.812 ; p<0.001)$ and CRP $(\beta=0.417,95 \% C I: 0.198-0.724 ; p<0.001)$. Evaluating CRP and miR-29c together ( $A \cup C=0.900, p<0.001$ ) achieved a better prognostic value for atherosclerosis than miR-29c (AUC $=0.870, p<0.001)$ or CRP $(A \cup C=0.722, p<0.001)$ alone. Conclusion: Increased miR-29c was closely associated with CIMT and may serve as a biomarker for identifying atherosclerotic patients.




\section{Cellular Physiology Cell Physiol Biochem 2018;50:452-459 \begin{tabular}{l|l|l} 
and Biochemistry 10.1159/000494158 & $\begin{array}{l}\text { (C) 2018 The Author(s). Published by S. Karger AG, Basel } \\
\text { www.karger.com/cpb }\end{array}$
\end{tabular}}

Huang et al.: miR-29c Levels Are Related to Carotid Intima Media Thickness

\section{Introduction}

Atherosclerotic cardiovascular disease and its clinical complications, including myocardial infarction and ischemic stroke, are the primary causes of human morbidity and mortality worldwide [1]. At the same time, macro-vascular diseases, which include coronary heart disease, carotid artery disease, peripheral vascular disease, and cerebral vessel disease, involve damage to large arteries and lead to important reactions and manifestations of atherosclerotic cardiovascular disease, such as carotid artery [2]. It is widely accepted that increased carotid intima thickness (CIMT) is a symptom of atherosclerosis, and this is often considered the most obvious and important clinical marker of subclinical variation or macrovascular damage [3]. Additionally, measuring CIMT is routinely used to assess subclinical atherosclerosis or atherosclerosis [4]. CIMT has been shown to predict cardiovascular risk in multiple large cohort studies and can be used to recommend asymptomatic adults at intermediate risk of cardiovascular diseases for cardiovascular risk assessment [5, 6]. Atherosclerosis development is complicated, but one important hypothesis is that atherosclerosis is initiated by the vascular infiltration of several inflammatory cell types and/or inflammatory reactions [7]. C-reactive protein (CRP) was identified in 1930 to be an "acute phase protein" that is an early and important indicator of infectious or inflammatory conditions [8]. In most cases, CRP levels are closely related to atherosclerotic cardiovascular disease, and CRP is also as a vital marker of carotid atherosclerosis progression [9].

Recently, a growing body of evidence has suggested that microRNAs (miRNAs) play vital roles in atherosclerosis development [10]. MiRNAs are a class of noncoding, single-stranded RNA molecules that are expressed in humans and involved in sequencespecific post-transcriptional regulation of gene expression [11]. MiRNAs have emerged as key players in a wide array of biological processes, and changes in their expression and/or function are associated with a plethora of human diseases $[11,12]$. Studies have shown that microRNAs regulate several cellular and molecular processes associated with atherosclerosis development, ranging from risk factors, to plaque initiation and progression, up to atherosclerotic plaque rupture [11,13]. Importantly, previous studies have revealed that miR-29c could play a multifaceted and important role in atherosclerosis formation [14].

Although it has been suggested that miR-29c could play vital roles in atherosclerosis formation, there is no data regarding associations between CRP or CIMT and miR-29c, and there is also no data regarding the prognostic value of miR-29c for identifying patients at risk for developing atherosclerosis. Thus, this study was conducted to investigate whether miR$29 \mathrm{c}$ levels differ between people with subclinical atherosclerosis to determine if circulating miR-29c could be a noninvasive marker for atherosclerosis in real-world population.

\section{Materials and Methods}

\section{Study population}

This was a cross-sectional study, and all participants are consecutively enrolled from the community, managed by Guangdong General Hospital (Guangdong, China). Patients with asymptomatic atherosclerosis were included, while patients with a history of coronary heart disease, cerebrovascular disease, diabetes mellitus, neck surgery, thyroid diseases, heavy smoking, cancer, carotid artery occlusion, acute infection disease, rheumatic immune disease, acute heart failure and relevant medications (lipid-lowering drugs, antiplatelet, or antihypertensive drugs, such as ACE/ARB, calcium channel/alpha/beta blockers or diuretic) were excluded. All participants underwent physical examinations and office blood pressure monitoring. Carotid arteries were examined using a standardized protocol. CIMT of the common carotid artery was measured using an ATL HDI 3000 ultrasound system (Advanced Technology Laboratories, Bothell, WA, USA) equipped with a $5 \mathrm{MHz}$ linear array transducer as previously described [15, 16]. According to the 2007 Guidelines for the management of arterial hypertension released by the Task Force for the Management of Arterial Hypertension of the European Society of Hypertension (ESH) and the European Society of Cardiology (ESC), subclinical atherosclerosis was defined as CIMT 0.9-1.2 mm, whereas atherosclerosis was defined as 


\section{Cellular Physiology Cell Physiol Biochem 2018;50:452-459 \begin{tabular}{l|l|l} 
DOI: 10.1159/000494158 & $\begin{array}{l}\text { O } 2018 \text { The Author(s). Published by S. Karger AG, Basel } \\
\text { www.karger.com/cpb }\end{array}$
\end{tabular} \\ Huang et al.: miR-29c Levels Are Related to Carotid Intima Media Thickness}

CIMT $\geq 1.2 \mathrm{~mm}$ [17]. The higher value between the left and right CIMT was used for analyses. A trained sonographer with registered diagnostic medical sonography certification performed all measurements. The glomerular filtration rate (GFR) was calculated by the Modification of Diet in Renal Disease Study Group [18]. This study was approved by the Medical Ethics Committee of Guangdong General Hospital, and written informed consent was obtained from each patient prior to participation. The study was conducted in accordance with the Declaration of Helsinki.

\section{Sample collection}

All samples were collected before treatment from patients and healthy volunteers in the morning after 12-14 h fasting. Plasma was extracted by centrifuging whole blood at 3, $000 \mathrm{rpm}$ for $10 \mathrm{~min}$ at room temperature; plasma samples were collected and divided into two aliquots, which were then stored at $-80^{\circ} \mathrm{C}$ for analysis. Fasting blood glucose, serum lipid, routine laboratory tests, and hepatic and renal functions were assayed using routine clinical laboratory methods.

\section{MiR-29c detection}

Total RNA containing small RNAs was extracted from plasma using TRIzol reagent (Invitrogen, Carlsbad, CA, USA) and purified with mirVana miR Isolation Kit (Ambion, Austin, TX, USA) according to the manufactures' protocols $[19,20]$. We evaluated the expression of plasma miRNAs using the S-Poly (T) RT-qPCR method as previously described [21], with miR-54 as an internal control [22]. Mean Ct values and deviations between duplicates were calculated for all samples using the following formula: $\Delta \mathrm{Ct}=\mathrm{Ct}(\mathrm{miR})$ Ct (miR-54). Primers used were 5' - uagcaccauuugaaaucgguua-3'for rmiR-29c. The relative miR expression level was determined using the formula $2-\Delta \Delta \mathrm{CT}$.

\section{Statistical analysis}

We found a sample size of $n=63$ per group is required to provide $80 \%$ power to detect a difference in the mean relative expression levels with a significance of $0.05(2$-sided $\alpha$ ). All continuous variables are expressed as mean \pm standard deviation. Normal distribution was tested using the Kolmogorov-Smirnov test. The chisquare test or Fisher's exact test was used to compare categorical variables. The Mann-Whitney U test or Student's $t$-test were used for continuous variables between patients and controls. Correlations between continuous variables were assessed using Spearman's correlation coefficient. Multiple linear regression analysis was used to assess relationships between miR-29c levels and CIMT or CRP. Age, body mass index, systolic blood pressure, and fasting blood glucose were adjusted. Statistical significance was defined as twosided $p<0.05$. The predictive value for diagnosing atherosclerosis was evaluated using receiver operating characteristic (ROC). Area under the ROC curve (AUC) was used as an accuracy index for evaluating the diagnostic performance of the selected clinical marker. ROC and regression analyses were performed using 21MedCalc software (version 10.4.7.0; MedCalc, Mariakerke, Belgium). All other statistical analyses were performed using SPSS software (version 17.0; SPSS Inc., Chicago, IL, USA) and GraphPad Prism 5 (GraphPad Software, La Jolla, CA, USA).

\section{Results}

Clinical characteristics, and plasma CRP and miR-29c levels

Baseline data for all patients are shown in Table 1; at baseline, we found that the age, sex, body mass index, fasting blood glucose, total cholesterol, high density lipoprotein cholesterol, low density lipoprotein cholesterol, triglyceride, glomerular filtration rate, diastolic blood pressure, and heart rate were not statistically different between the groups, while CRP, systolic blood pressure, and miR-29c were significantly different; the study group showed higher CRP and miR-29c relative expression levels, compared with the control group (Fig. $1 \mathrm{~A}$ and $1 \mathrm{~B}$ ).

Associations between miR-29c and CRP with CIMT

As is shown in Table 2, CIMT was positively correlated with miR-29c $(r=0.659, \mathrm{p}<0.001)$, systolic blood pressure $(r=0.412, p<0.001)$, total cholesterol $(r=0.224, p=0.004)$ and CRP 
Table 1. Demographic, clinic and laboratory characteristics between groups. HDL-C, highdensity lipoprotein cholesterol; LDL-C, low density lipoprotein cholesterol; GFR, glomerular filtration rate; CRP, C-reactive protein; DBP, diastolic blood pressure; SBP, systolic blood pressure. Data are presented as the mean \pm standard deviation

\begin{tabular}{lccc}
\hline & $\begin{array}{c}\text { Study group } \\
(\mathrm{n}=85)\end{array}$ & $\begin{array}{c}\text { Control group } \\
(\mathrm{n}=85)\end{array}$ & p-value \\
& $41 / 44$ & $46 / 39$ & 0.105 \\
\hline Males/females & $50.48 \pm 5.78$ & $51.22 \pm 5.42$ & 0.470 \\
Age (years) & $26.54 \pm 3.42$ & $26.85 \pm 3.80$ & 0.411 \\
Body mass index (kg/m²) & $200.40 \pm 45.72$ & $192.94 \pm 38.00$ & 0.094 \\
Total cholesterol (mg/dl) & $50.46 \pm 13.15$ & $49.30 \pm 11.25$ & 0.711 \\
HDL-C(mg/dl) & $127.16 \pm 33.71$ & $123.41 \pm 33.52$ & 0.839 \\
LDL-C(mg/dl) & $179.64 \pm 55.84$ & $153.86 \pm 59.74$ & 0.186 \\
Triglyceride (mg/dl) & $111.32 \pm 11.65$ & $111.06 \pm 13.85$ & 0.278 \\
GFR(ml/min/1.73m²) & $4.92 \pm 0.49$ & $5.01 \pm 0.53$ & 0.349 \\
Fasting blood-glucose(mmol/l) & $74.69 \pm 10.82$ & $74.89 \pm 9.53$ & 0.125 \\
Heart rate(beats/minute) & $141.02 \pm 12.05$ & $136.55 \pm 15.66$ & $<0.001$ \\
SBP(mm Hg) & $84.95 \pm 8.49$ & $83.42 \pm 9.23$ & 0.328 \\
DBP(mm Hg) & $17.34 \pm 5.48$ & $6.83 \pm 2.89$ & $<0.001$ \\
CRP(mg/l) & & & \\
miR-29c relative & $3.81 \pm 1.38$ & $1.89 \pm 0.86$ & $<0.001$ \\
expression level (fold change) & & & \\
\hline
\end{tabular}

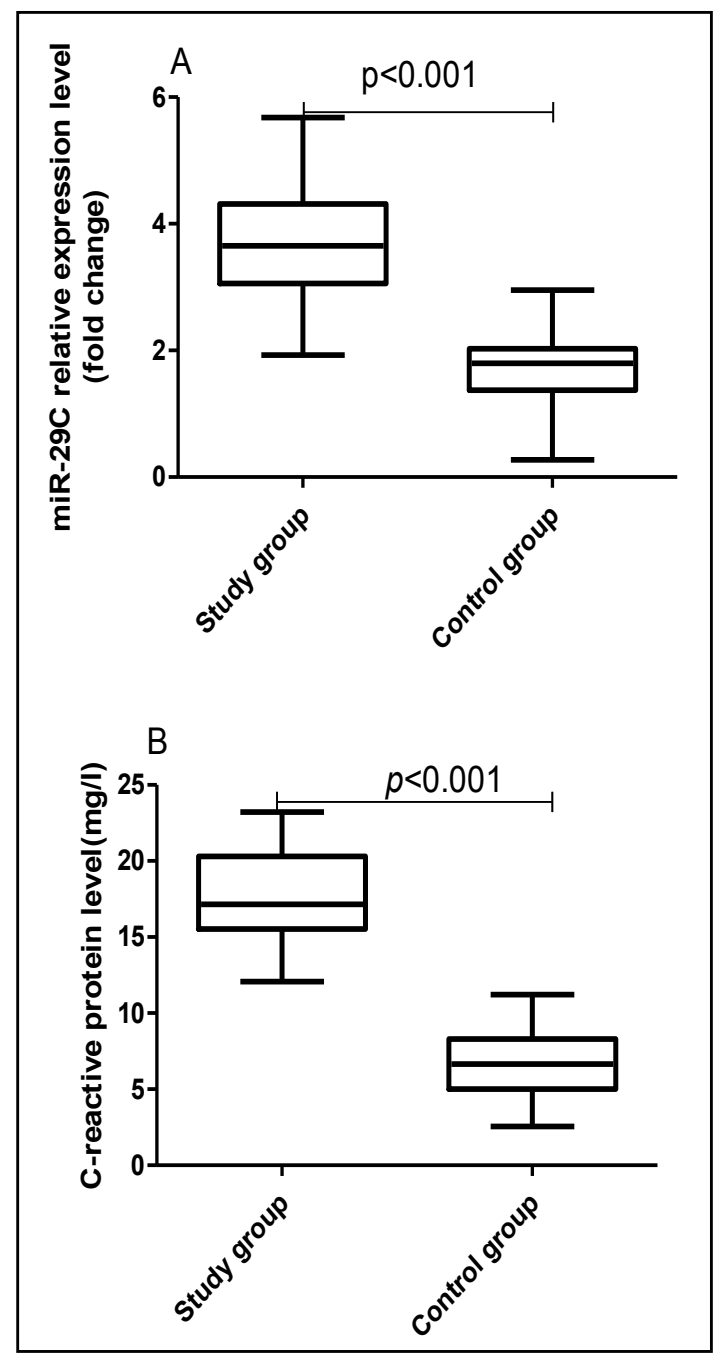

Fig. 1. A. miR-29c levels in study group and control group; B. C-reactive protein expression levels in study group and control group.

$(\mathrm{r}=0.447, \mathrm{p}<0.001)$, and miR-29c levels were also correlated with $\mathrm{CRP}(\mathrm{r}=0.512, \mathrm{p}<0.001)$ and systolic blood pressure $(r=0.332, p<0.001)$. Additionally, multiple linear regression showed that CIMT was positively correlated with miR-29c $(\beta=0.573,95 \%$ confidence interval [CI]: $0.315-0.839 ; \mathrm{p}<0.001)$ and CRP $(\beta=0.439,95 \%$ CI: 0.186-0.825; $\mathrm{p}<0.001)$. After adjusting for age, body mass index, systolic blood pressure, total cholesterol, and fasting blood glucose, CIMT was still closely associated with miR-29c $(\beta=0.529,95 \% \mathrm{CI}: 0.354-0.812 ; \mathrm{p}<0.001)$ and CRP ( $\beta=0.417,95 \%$ CI: 0.198-0.724; $p<0.001)$ ( Table 3).

\section{Predictive value of miR-29c and CRP for subclinical atherosclerosis}

Next, we performed a ROC analysis to determine the predictive values of miR-29c and CRP for subclinical atherosclerosis. We found that the combination of miR-29c and CRP (AUC=0.900, 95\% CI: 0.857-0.944; sensitivity $=97.5 \%$, specificity $=68.8 \%$; $p<0.001$ ) offered a better predictive value for subclinical atherosclerosis than either miR-29c (AUC $=0.870,95 \%$ CI: $0.818-0.922$; sensitivity $=96.3 \%$, specificity $=56.9 \%$; $p<0.001)$ or CRP $(A U C=0.722,95 \%$ CI: $0.650-0.793$; sensitivity $=88.8 \%$, specificity $=63.3 \%$; $p<0.001$ ) alone. Thus, the diagnostic performance of miR-29c and CRP together was superior to miR-29c or CRP independently (Fig. 2). 
Table 2. Relationship of miR-29c expression level with C-reactive protein and CIMT. HDL-C, highdensity lipoprotein cholesterol; LDL-C, low density lipoprotein cholesterol; CIMT; carotid intima-media thickness; CRP, C-reactive protein. The Spearman correlation coefficient was used for statistical analysis

\begin{tabular}{|c|c|c|c|c|}
\hline & miR-29c & & CIMT & \\
\hline & $\mathrm{r}$ & $\mathrm{p}$ & $\mathrm{r}$ & $\mathrm{p}$ \\
\hline miR-29c & & & 0.659 & $<0.001$ \\
\hline CRP & 0.512 & $<0.001$ & 0.447 & $<0.001$ \\
\hline Systolic blood pressure & 0.332 & $<0.001$ & 0.412 & $<0.001$ \\
\hline Diastolic blood pressure & 0.103 & 0.189 & 0.102 & 0.158 \\
\hline Fasting blood-glucose & 0.072 & 0.487 & 0.056 & 0.552 \\
\hline Age & 0.087 & 0.367 & 0.074 & 0.416 \\
\hline Body mass index & 0.059 & 0.581 & 0.079 & 0.401 \\
\hline Total cholesterol & 0.106 & 0.114 & 0.224 & 0.004 \\
\hline HDL-C & 0.054 & 0.598 & -0.089 & 0.389 \\
\hline LDL-C & 0.103 & 0.221 & 0.175 & 0.197 \\
\hline Triglyceride & 0.125 & 0.179 & 0.116 & 0.201 \\
\hline
\end{tabular}

Table 3. Relation of C-reactive protein and miR-29c with carotid intima media thickness. CRP, C-reactive protein. Multivariate linear regression analysis was used for statistical analysis .Model1: It was a standard model, Model2: Age, BMI, SBP, TC and fasting blood-glucose were adjusted

\begin{tabular}{ccccc}
\hline & & $\beta$ & $\mathrm{p}$ & $95 \% \mathrm{CI}$ \\
\hline Model1 & miR-29c & 0.573 & $<0.001$ & $0.315,0.839$ \\
& CRP & 0.439 & $<0.001$ & $0.186,0.825$ \\
Model2 & miR-29c & 0.529 & $<0.001$ & $0.354,0.812$ \\
& CRP & 0.417 & $<0.001$ & $0.198,0.724$ \\
& & & & \\
\hline
\end{tabular}

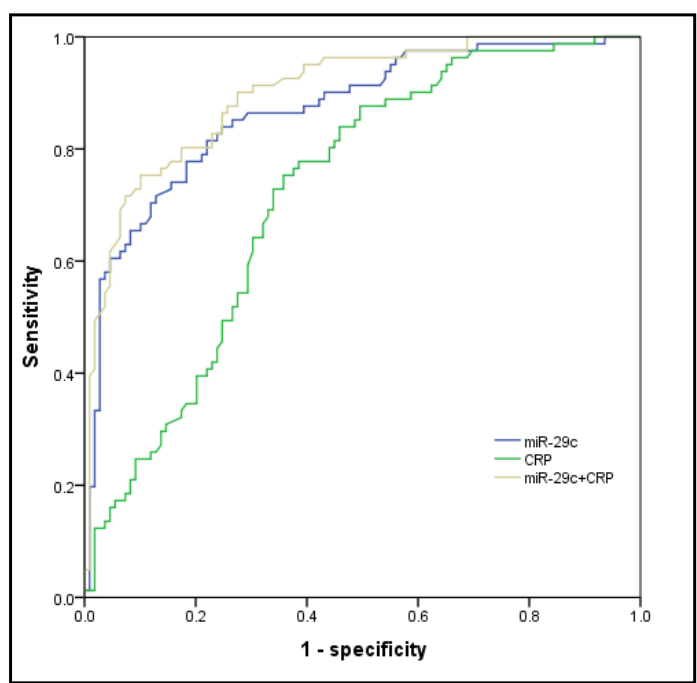

Fig. 2. ROC curve for atherosclerosis. CRP, C-reactive protein.

\section{Discussion}

In this study, we found that plasma miR-29c and CRP levels were higher in the study group compared with controls. CIMT was positively correlated with miR-29c and CRP, and miR-29c levels were also correlated with CRP. Importantly, these correlations were independent of age, body mass index, systolic blood pressure, total cholesterol, and fasting blood glucose in multivariate analysis. To the best of our knowledge, this study is the first to indicate that plasma miR-29c could be an independent predictor of subclinical atherosclerosis. Furthermore, the combined AUC of miR-29c and CRP was a better indicator of preclinical atherosclerosis than the AUC of either miR-29c or CRP alone.

It is generally accepted that atherosclerosis is a chronic inflammatory disease that is one of the leading risk factors for cardiovascular and/or cerebrovascular diseases [23]. Moreover, a growing body of recent data has shown that circulating miRs could influence the development and progression of vascular diseases, including atherosclerosis [24, 25]. Although atherosclerosis is common in clinical practice, the mechanisms of its genesis have 


\section{Cellular Physiology Cell Physiol Biochem 2018;50:452-459 \begin{tabular}{ll|l} 
DOI: 10.1159/000494158 & $\begin{array}{l}\text { O 2018 The Author(s). Published by S. Karger AG, Basel } \\
\text { www.karger.com/cpb }\end{array}$
\end{tabular} \\ Huang et al.: miR-29c Levels Are Related to Carotid Intima Media Thickness}

not been fully elucidated. A previous study revealed that miR-29c was closely associated with atherosclerosis through several different mechanisms [26]. We found that miR-29c levels were higher in patients with increased CIMT than in those with normal CIMT values. At the same time, vascular inflammation in atheroprone vessels propagates throughout the arterial tree in dyslipidemic patients, thereby accelerating atherosclerotic progression [27]. CRP is one of the most commonly used biomarkers for inflammation in clinical practices. Several studies have shown that CRP is a potent risk factor that can independently predict future cardiovascular events, and is closely associated with an increased risk of target organ damage, such as atherosclerosis [28]. In this study, we also demonstrated that CRP levels were positively correlated with CIMT, which has been recommended for measuring cardiovascular and cerebrovascular risk in the general population.

Inflammatory responses are an important aspect of atherosclerosis. We found that miR-29c levels were significantly correlated with the key inflammatory factor CRP. The phenotypic transformation and dysfunction of vascular smooth muscle cells, endothelial cells, and macrophages, such as abnormal proliferation and apoptosis, are a key pathological basis of atherosclerosis [29]. Previous studies have demonstrated that miR-29 regulates atherosclerosis by modulating miRNA targets that encode extracellular matrix proteins (e.g., collagen A and collagen 3A) [26]. Additionally, miR-29c could inhibit endotheliocyte migration and angiogenesis of human endothelial cells by suppressing the insulin like growth factor 1 [30]. Khorram 0 et al. also found that miR-29 played vital roles in atherosclerosis by regulating the expression of extracellular matrix [31]. These preclinical studies indicated that miR-29c could play several distinct roles during atherosclerosis development; thus, they provide underlying molecular mechanisms for our results.

This study had a few limitations. First, we evaluated miR-29c and CRP levels only from cross-sectional participants, we did not evaluate these during the prospective follow-up period, so we cannot draw causal conclusions about miR-29c directly leading to atherosclerosis. Second, we only used the inflammatory factor CRP to evaluate inflammatory conditions. Third, the number of study subjects was relatively small, and multicenter, prospective studies with larger sample sizes are needed to confirm our results. In addition, potential mechanisms linking miR-29c and CIMT were not elucidated, and this will require more preclinical studies in the future. Finally, we studied only miR-29c in our research. But many previous basic studies from references indicated that miR-29c may play an important role in the development of atherosclerosis through many mechanisms [14, 30,31]. Therefore, those basic researches mentioned in the previous literatures provided a certain theoretical guarantee for our conclusion.

\section{Conclusion}

All in all, increased plasma miR-29c levels were independently associated with CIMT in a community population. Plasma miR-29c levels were closely associated with the inflammatory marker, CRP, which indicated that miR-29c may play an important role in atherosclerosis development. Thus, this novel marker may be useful for predicting the development of subclinical atherosclerosis or atherosclerosis and may further contribute to risk stratification.

\section{Acknowledgements}

This work was supported by the Natural Science Foundation of Guangdong Province (No. 2015A030313660), the Science and Technology Program of Guangdong Province (No. 2014B020212008), the Science and Technology Program of Guangzhou (No.201604020143, No. 201604020018, No. 201604020186, No. 201510010254, No. 201803030012), the National Key Research and Development Program of China (No. 2017FYC1307603, No. 


\section{Cellular Physiology Cell Physiol Biochem 2018;50:452-459 \begin{tabular}{ll|l} 
DOI: 10.1159/000494158 & $\begin{array}{l}\text { O } 2018 \text { The Author(s). Published by S. Karger AG, Basel } \\
\text { www.karger.com/cpb }\end{array}$ \\
\hline and Biochemistry Published online: 11 October 2018 &
\end{tabular}}

Huang et al.: miR-29c Levels Are Related to Carotid Intima Media Thickness

2016YFC1301305), the Medical Science and Technology Research Fund of Guangdong Province (No. B2018023), the Science, Technology Program of Guangdong Province (No. 2014B020212008) and National Natural Science Foundation of China (No. 81300230).

\section{Disclosure Statement}

The authors declare that no competing interests exist.

\section{References}

1 Ference BA, Ginsberg HN, Graham I, Ray KK, Packard CJ, Bruckert E, Hegele RA, Krauss RM, Raal FJ, Schunkert H, Watts GF, Boren J, Fazio S, Horton JD, Masana L, Nicholls SJ, Nordestgaard BG, van de Sluis B, Taskinen MR, Tokgozoglu L et al.: Low-density lipoproteins cause atherosclerotic cardiovascular disease. 1. Evidence from genetic, epidemiologic, and clinical studies. A consensus statement from the European Atherosclerosis Society Consensus Panel. Eur Heart J 2017;38:2459-2472.

-2 Rostampour N, Fekri K, Hashemi-Dehkordi E, Obodiat M: Association between Vascular Endothelial Markers and Carotid Intima-Media Thickness in Children and Adolescents with Type 1 Diabetes Mellitus. J Clin Diagn Res 2017;11:C1-C5.

-3 Celermajer DS, Sorensen KE, Gooch VM, Spiegelhalter DJ, Miller OI, Sullivan ID, Lloyd JK, Deanfield JE: Non-invasive detection of endothelial dysfunction in children and adults at risk of atherosclerosis. Lancet 1992;340:1111-1115.

-4 Stein JH, Korcarz CE, Post WS: Use of carotid ultrasound to identify subclinical vascular disease and evaluate cardiovascular disease risk: summary and discussion of the American Society of Echocardiography consensus statement. Prev Cardiol 2009;12:34-38.

-5 Stein JH, Korcarz CE, Hurst RT, Lonn E, Kendall CB, Mohler ER, Najjar SS, Rembold CM, Post WS: Use of carotid ultrasound to identify subclinical vascular disease and evaluate cardiovascular disease risk: a consensus statement from the American Society of Echocardiography Carotid Intima-Media Thickness Task Force. Endorsed by the Society for Vascular Medicine. J Am Soc Echocardiogr 2008;21:93-111, 189-190.

6 Huang YQ, Cai AP, Chen JY, Huang C, Li J, Feng YQ: The Relationship of Plasma miR-29a and Oxidized Low Density Lipoprotein with Atherosclerosis. Cell Physiol Biochem 2016;40:1521-1528.

7 Husain K, Hernandez W, Ansari RA, Ferder L: Inflammation, oxidative stress and renin angiotensin system in atherosclerosis. World J Biol Chem 2015;6:209-217.

8 Clyne B, Olshaker JS: The C-reactive protein. J Emerg Med 1999;17:1019-1025.

-9 Pleskovic A, Letonja MS, Vujkovac AC, Nikolajevic SJ, Gazdikova K, Caprnda M, Gaspar L, Kruzliak P, Petrovic D: C-reactive protein as a marker of progression of carotid atherosclerosis in subjects with type 2 diabetes mellitus. Vasa 2017;46:187-192.

10 Koroleva IA, Nazarenko MS, Kucher AN: Role of microRNA in Development of Instability of Atherosclerotic Plaques. Biochemistry (Mosc) 2017;82:1380-1390.

11 Laffont B, Rayner KJ: MicroRNAs in the Pathobiology and Therapy of Atherosclerosis. Can J Cardiol 2017;33:313-324.

12 Papageorgiou N, Tsalamandris S, Giolis A, Tousoulis D: MicroRNAs in Cardiovascular Disease: Perspectives and Reality. Cardiol Rev 2016;24:110-118.

13 Giral H, Kratzer A, Landmesser U: MicroRNAs in lipid metabolism and atherosclerosis. Best Pract Res Clin Endocrinol Metab 2016;30:665-676.

14 Kriegel AJ, Liu Y, Fang Y, Ding X, Liang M: The miR-29 family: genomics, cell biology, and relevance to renal and cardiovascular injury. Physiol Genomics 2012;44:237-244.

15 Cardellini M, Marini MA, Frontoni S, Hribal ML, Andreozzi F, Perticone F, Federici M, Lauro D, Sesti G: Carotid artery intima-media thickness is associated with insulin-mediated glucose disposal in nondiabetic normotensive offspring of type 2 diabetic patients. Am J Physiol Endocrinol Metab 2007;292:E347-E352. 


\section{Cellular Physiology Cell Physiol Biochem 2018;50:452-459 \begin{tabular}{l|l|l} 
DOI: 10.1159/000494158 & $\begin{array}{l}\text { O } 2018 \text { The Author(s). Published by S. Karger AG, Basel } \\
\text { www.karger.com/cpb }\end{array}$
\end{tabular}}

Huang et al.: miR-29c Levels Are Related to Carotid Intima Media Thickness

16 Polak JF, Pencina MJ, Meisner A, Pencina KM, Brown LS, Wolf PA, D’Agostino RS: Associations of carotid artery intima-media thickness (IMT) with risk factors and prevalent cardiovascular disease: comparison of mean common carotid artery IMT with maximum internal carotid artery IMT. J Ultrasound Med 2010;29:1759-1768.

17 Mancia G, De Backer G, Dominiczak A, Cifkova R, Fagard R, Germano G, Grassi G, Heagerty AM, Kjeldsen SE, Laurent S, Narkiewicz K, Ruilope L, Rynkiewicz A, Schmieder RE, Struijker BH, Zanchetti A, Vahanian A, Camm J, De Caterina R et al., The TFFT: 2007 Guidelines for the management of arterial hypertension: The Task Force for the Management of Arterial Hypertension of the European Society of Hypertension (ESH) and of the European Society of Cardiology (ESC). Eur Heart J 2007;28:1462-1536.

$\checkmark 18$ Levey AS, Bosch JP, Lewis JB, Greene T, Rogers N, Roth D: A more accurate method to estimate glomerular filtration rate from serum creatinine: a new prediction equation. Modification of Diet in Renal Disease Study Group. Ann Intern Med 1999;130:461-470.

19 Mitchell PS, Parkin RK, Kroh EM, Fritz BR, Wyman SK, Pogosova-Agadjanyan EL, Peterson A, Noteboom J, O’Briant KC, Allen A, Lin DW, Urban N, Drescher CW, Knudsen BS, Stirewalt DL, Gentleman R, Vessella RL, Nelson PS, Martin DB, Tewari M: Circulating microRNAs as stable blood-based markers for cancer detection. Proc Natl Acad Sci U S A 2008;105:10513-10518.

20 Huang Y, Chen J, Zhou Y, Tang S, Li J, Yu X, Mo Y, Wu Y, Zhang Y, Feng Y: Circulating miR155 expression level is positive with blood pressure parameters: Potential markers of target-organ damage. Clin Exp Hypertens 2016;38:331-336.

21 Kang K, Zhang X, Liu H, Wang Z, Zhong J, Huang Z, Peng X, Zeng Y, Wang Y, Yang Y, Luo J, Gou D: A novel real-time PCR assay of microRNAs using S-Poly(T), a specific oligo(dT) reverse transcription primer with excellent sensitivity and specificity. Plos One 2012;7:e48536-e48546.

22 Baraniskin A, Nopel-Dunnebacke S, Ahrens M, Jensen SG, Zollner H, Maghnouj A, Wos A, Mayerle J, Munding J, Kost D, Reinacher-Schick A, Liffers S, Schroers R, Chromik AM, Meyer HE, Uhl W, Klein-Scory S, Weiss FU, Stephan C, Schwarte-Waldhoff I et al.: Circulating U2 small nuclear RNA fragments as a novel diagnostic biomarker for pancreatic and colorectal adenocarcinoma. Int J Cancer 2013;132:E48-E57.

23 Tunstall-Pedoe H, Vanuzzo D, Hobbs M, Mahonen M, Cepaitis Z, Kuulasmaa K, Keil U: Estimation of contribution of changes in coronary care to improving survival, event rates, and coronary heart disease mortality across the WHO MONICA Project populations. Lancet 2000;355:688-700.

24 Huang SC, Wang M, Wu WB, Wang R, Cui J, Li W, Li ZL, Li W, Wang SM: Mir-22-3p Inhibits Arterial Smooth Muscle Cell Proliferation and Migration and Neointimal Hyperplasia by Targeting HMGB1 in Arteriosclerosis Obliterans. Cell Physiol Biochem 2017;42:2492-2506.

25. Zhang T, Tian F, Wang J, Jing J, Zhou SS, Chen YD: Atherosclerosis-Associated Endothelial Cell Apoptosis by MiR-429-Mediated Down Regulation of Bcl-2. Cell Physiol Biochem 2015;37:1421-1430.

-26 Ulrich V, Rotllan N, Araldi E, Luciano A, Skroblin P, Abonnenc M, Perrotta P, Yin X, Bauer A, Leslie KL, Zhang P, Aryal B, Montgomery RL, Thum T, Martin K, Suarez Y, Mayr M, Fernandez-Hernando C, Sessa WC: Chronic miR-29 antagonism promotes favorable plaque remodeling in atherosclerotic mice. Embo Mol Med 2016;8:643-653.

-27 Miyazaki T, Miyazaki A: Defective Protein Catabolism in Atherosclerotic Vascular Inflammation. Front Cardiovasc Med 2017;4:79-89.

-28 Bisoendial RJ, Boekholdt SM, Vergeer M, Stroes ES, Kastelein JJ: C-reactive protein is a mediator of cardiovascular disease. Eur Heart J 2010;31:2087-2091.

29 Shen L, Song Y, Fu Y, Li P: MiR-29b mimics promotes cell apoptosis of smooth muscle cells via targeting on MMP-2. Cytotechnology 2018;70:351-359.

30 Hu Y, Deng F, Song JL, Lin JH, Li X, Tang YY, Zhou J, Tang T, Zheng LL: Evaluation of miR-29c inhibits endotheliocyte migration and angiogenesis of human endothelial cells by suppressing the insulin like growth factor 1. Am J Transl Res 2015;7:866-877.

-31 Khorram 0, Chuang TD, Pearce WJ. Long-term effects of maternal undernutrition on offspring carotid artery remodeling: role of miR-29c. J Dev Orig Health Dis 2015;6:342-349. 